\title{
Erythropoietin Enhances Long-Term Neuroprotection and Neurogenesis in Neonatal Stroke
}

\author{
Fernando F. Gonzalez ${ }^{a, b}$ Patrick McQuillen ${ }^{a}$ Dezhi Mub,d Yunsil Chang ${ }^{b, e}$ \\ Michael Wendland ${ }^{c}$ Zinaida Vexler $^{\mathrm{b}}$ Donna M. Ferriero ${ }^{\mathrm{a}, \mathrm{b}}$ \\ Departments of a Pediatrics, ${ }^{b}$ Neurology, and ' Radiology, University of California, San Francisco, Calif., USA; \\ ${ }^{\mathrm{d}}$ Department of Pediatrics, West China Second University Hospital, Sichuan University, Chengdu, China; \\ e Department of Pediatrics, Samsung Medical Center, Sungkyunkwan University School of Medicine, Seoul, \\ South Korea
}

\section{Key Words}

Ischemia $\cdot$ Neonatal brain injury $\cdot$ Neonatal stroke $\cdot$ Cell

fate $\cdot$ Stem cell $\cdot$ Neurogenesis

\begin{abstract}
Neonatal stroke leads to mortality and severe morbidity, but there is no effective treatment currently available. Erythropoietin (EPO) has been shown to promote cytoprotection and neurogenesis and decrease subventricular zone morphologic changes following brain injury. The long-term cellular response to EPO has not been defined, and local changes in cell fate decision may play a role in functional improvement. We performed middle cerebral artery occlusion in P10 rats. EPO treatment $(5 \mathrm{U} / \mathrm{g} \mathrm{IP})$ significantly preserved hemispheric brain volume 6 weeks after injury. Furthermore, EPO increased the percentage of newly generated neurons while decreasing newly generated astrocytes following brain injury, without demonstrating long-term differences in the subventricular zone. These results suggest that EPO may neuroprotect and direct cell fate toward neurogenesis and away from gliogenesis in neonatal stroke.
\end{abstract}

Copyright $\odot 2007$ S. Karger AG, Basel

\section{KARGER}

Fax +4161306 1234

E-Mail karger@karger.ch

www.karger.com
(C) 2007 S. Karger AG, Basel

Accessible online at: www.karger.com/dne

\section{Introduction}

Stroke occurs in approximately 1 in 4,000 live fullterm births [1]. This leads to adverse changes in central nervous system development and, consequently, increased mortality and long-term neurological morbidity. Despite these lifelong effects, no adequate postinjury strategy for treatment is currently available.

We have previously described a nonhemorrhagic stroke model in the neonatal rat using transient middle cerebral artery occlusion (MCAO) $[2,3]$. This ischemiareperfusion injury results in damage to the ipsilateral striatum and parietotemporal cortex. Erythropoietin (EPO) has been shown to play an important role in neuronal survival in both mature and immature rodent models of brain injury [4-11]. Recent studies also demonstrate a beneficial effect of exogenous EPO administration in reducing infarct volume [12], and improving short and long-term functional performance [12-14]. EPO may mediate protection via downregulation of proapoptotic genes $[15,16]$, modulation of the inflammatory response [17-19], reduction of glutamate toxicity [5, 20-22], vasoactive and proangiogenic effects $[13,23,24]$, or direct stimulation of neuronal production from precursors $[25$, 26]. 
Focal ischemic injury has been found to temporarily stimulate precursor cell proliferation in the adult rodent forebrain subventricular zone (SVZ), which is a germinative area for new neurons that migrate to the olfactory bulb throughout life [27-30]. EPO is known to promote neurogenesis in vitro and in vivo [25], and has also been shown to enhance neurogenesis in the SVZ following stroke in the adult rat [13]. We have also seen increased SVZ hypertrophy at an early time point in neonatal rodents, 2 weeks following MCAO, but response was decreased in EPO-treated rats [12], possibly from enhanced early migration of cells or decreased SVZ response secondary to preservation of local tissue.

Given the changes in infarct and SVZ volumes observed with exogenous EPO, a question arises regarding this preserved tissue, and what types of cells populate the injured area. Neurogenesis has been demonstrated following EPO treatment with an increase in newly generated cells from precursors $[13,25,26]$, and possibly also an effect on cell fate in vitro $[13,25]$. However, a variety of cell types besides neurons express EPO and EPO receptor (EPO-R) following brain injury [5], including astrocytes, endothelial cells, and microglia, and a glial response may play a role in volume preservation after injury. We set out to determine if EPO alters cell fate decision 6 weeks after transient MCAO by quantifying the proportion of newly generated neurons and astrocytes in the injured areas, and we used unbiased stereology to calculate preserved brain volume in vehicle and EPO-treated brains.

\section{Materials and Methods}

The University of California, San Francisco Institutional Animal Care and Use Committee approved all animal research, and every effort was made to minimize animal suffering and reduce the number of animals used.

\section{Cerebral Focal Ischemia - Reperfusion}

All surgical procedures were performed in 10-day-old SpragueDawley rats; this age was chosen to approximate the development of the term human newborn [31]. Female rats with an 8- to 9-day old litter ( $\sim 10$ pups per litter) were bought from Simonson Labs (Gilroy, Calif., USA). Mothers were housed in a temperature and light-controlled facility and given food and water until pups were 10 days old. Transient focal cerebral ischemia was produced using the MCAO method with some modifications [2, 3]. Briefly, each pup was weighed and anesthetized with $3 \%$ isoflurane in a mixture of $70 \% \mathrm{~N}_{2} \mathrm{O}$ and $30 \% \mathrm{O}_{2}$. Following induction of anesthesia, $1.5 \%$ isoflurane was maintained and rectal temperature was monitored and maintained at $36-37^{\circ} \mathrm{C}$ with a combination of heating blanket and overhead light. With the animal supine, the right common carotid artery, external carotid artery (ECA), and inter- nal carotid artery were exposed with a midline cervical incision. The pterygopalatine, occipital, superior thyroid, maxillary, and lingual arteries were coagulated. After ligation of the ECA, a 5-0 nylon monofilament suture with blunted tip was inserted into the ECA lumen and gently advanced through the internal carotid artery up to the middle cerebral artery until slight resistance was felt. Sham controls did not have the suture advanced. After placement of the suture, the wound was closed.

\section{MR Imaging and EPO Treatment}

Each animal was examined by diffusion-weighted spin echo planar imaging (SE EPI) at 25-30 min after MCAO. The entire brain was imaged with serial 2-mm thick coronal sections as previously described $[2,12]$ using the following pulse sequence settings: $\mathrm{TR} / \mathrm{TE}=5,000 / 60 \mathrm{~ms}, 4$ averages, field of view $=35 \mathrm{~mm}$, data matrix $128 \times 128$, diffusion gradient duration $=20 \mathrm{~ms}$, separation $=29.7 \mathrm{~ms}$, amplitude $=70 \mathrm{mT} / \mathrm{m}$, b-factor $=1,045 \mathrm{~s} / \mathrm{mm}^{2}$. Reperfusion was achieved after $45 \mathrm{~min}$ of occlusion by removing the suture under isoflurane anesthesia. In a previous study, we found that an occlusion time of $45 \mathrm{~min}$ produced a moderate level of injury involving the ipsilateral striatum and parietotemporal cortex, and reperfusion was confirmed with contrast study [12] . Animals that exhibited ischemic injury in atypical regions, such as brainstem, or that showed lack of cortical involvement were excluded from the study. Immediately upon reperfusion, a single dose of either vehicle $[0.1 \%$ bovine serum albumin (Sigma, St. Louis, Mo., USA) in saline] or recombinant human EPO (a gift from Johnson and Johnson) at a dose of 5 units per gram of body weight was injected intraperitoneally. Following surgery, animals recovered from anesthesia and were returned to the dam until weaning. Most pups that received MCAO at P10 showed poor suckling during the first 2-3 days following surgery and were gavage fed, with daily weights measured for the first week to ensure adequate weight gain. All animals were injected with BrdU (5bromo-2'-deoxy-uridine; Roche, Indianapolis, Ind., USA) at a dose of $50 \mathrm{mg} / \mathrm{kg} / \mathrm{dose}$ twice per day on post-MCAO days 7 through 9. This dosing regimen was chosen to limit labeling of proliferating glial cells just after brain injury, and for the maximal period of neurogenesis following adult brain injury [32].

\section{Histology}

For histopathologic examination, animals were anesthetized with sodium pentobarbital (100 mg/kg; Nembutal, Abbott Labs, Abbott Park, Ill., USA) and sacrificed 6 weeks following surgery by transcardiac perfusion with ice-cold $4 \%$ paraformaldehyde in $0.1 \mathrm{M}$ phosphate buffered saline (PBS, $\mathrm{pH} 7.4$ ). Brains were carefully removed and postfixed overnight, equilibrated in $30 \%$ sucrose in $0.1 \mathrm{M}$ PBS and left at $4^{\circ} \mathrm{C}$ for a maximum of $72 \mathrm{~h}$. Freefloating serial $40-\mu \mathrm{m}$ coronal sections were collected throughout the brain in each animal using a freezing microtome. Sections were stored at $4^{\circ} \mathrm{C}$ in $0.1 \mathrm{M}$ phosphate buffer with $0.1 \%$ sodium azide for a maximum of 2 weeks or stored in cryoprotectant at $-20^{\circ} \mathrm{C}$ until staining.

Volumetric Analysis of Bilateral Brain Hemispheres and SVZ

For volumetric analysis, sections were mounted and air-dried, stained with cresyl violet, dehydrated in graded ethanol solutions, cleared in Citrisolv (Fisher Scientific, Pittsburgh, Pa., USA) and cover-slipped in Permount (Fisher Scientific, Pittsburgh, Pa., USA). Using systematic random sampling, a series representing 
every 12 th section was selected, stained, and analyzed. Sections encompassed the whole striatum from the genu of the corpus callosum rostrally to the rostral hippocampus caudally. Volumetric quantifications were performed using a Nikon Eclipse E600 photomicroscope equipped with a high-resolution CCD camera, a motorized XYZ axis computer-controlled stage, and Neurolucida and Neuroexplorer morphometry software package (MicroBrightField, Inc., Colchester, Vt., USA). The cross-sectional areas of the region of interest (ROI) in each section was traced on the computer screen at low power using a $2 \times / 4 \times$ lens and the volume of the ROI was calculated according to the Cavalieri principle [33]. For the ROI, the right and left hemisphere and SVZ were traced. Morphological criteria were used consistently in all animals to determine the boundaries of the SVZ. Dorsolateral striatal extension of the SVZ was outlined, which resembles the dark band and thin long triangle in the sections corresponding to Plate 10-20 of the Paxinos Rat Brain Atlas [34]. Briefly, the superiormedial boundary of the SVZ was defined by the corpus callosum, the lateral boundary by the striatum, and the inferior boundary by the lateral ventricular margin. By using this sampling strategy, approximately 11 histological sections per brain for hemispheric measurement and 6 sections per brain for SVZ measurements were analyzed. Quantification was conducted by an examiner blinded to treatment group. Damage due to stroke was determined quantitatively by calculating the percent preserved volume in the ipsilateral, or lesioned, hemisphere vs. the contralateral, control hemisphere. Size alteration of SVZ was investigated by calculating the percent SVZ volume in lesioned vs. control hemisphere in each animal.

\section{Immunophenotyping and Confocal Analysis}

For quantititative analysis of cell types, the entire striatum was sectioned coronally and a systematic random sampling of every 24 th section (3-4 sections per animal) was double-immunostained for BrdU/NeuN, or BrdU/GFAP. Briefly, after overnight incubation in either mouse anti-NeuN (1:800, Chemicon, Temecula, Calif., USA) or rabbit anti-GFAP (1:400, Chemicon, Temecula, Calif., USA), sections were fixed in $4 \%$ PFA, denatured by incubation in $2 \mathrm{M}$ hydrochloric acid at $37^{\circ} \mathrm{C}$ for $30 \mathrm{~min}$, washed in $0.1 \mathrm{M}$ Borate buffer and blocked in $25 \%$ goat serum (in TBS with $0.1 \%$ Triton-X) for $1 \mathrm{~h}$ before BrdU staining. Sections were incubated overnight with rat anti-BrdU (1:200, Abcam, Cambridge, Mass., USA) and NeuN or GFAP in blocking solution. Sections were rinsed and incubated for $1 \mathrm{~h}$ with goat anti-rat Alexa 594 (1:800, Molecular Probes, Eugene, Oreg., USA) and Alexa $488 \mathrm{sec}-$ ondary antibodies in blocking solution. Sections were then mounted on Superfrost slides (Fisher Scientific, Pittsburgh, Pa., USA) and coverslipped using Vectashield (Vector Laboratories, Burlingame, Calif., USA).

Double-immunostained sections were imaged using a confocal scanning laser microscope (Zeiss LSM 510, Jena, Germany) at $20 \times$ objective (Plan-Apo lens, NA 0.75, camera resolution 1,024 $\times 1,024$ pixels, field dimensions $412 \times 412 \times 25 \mu \mathrm{m}$ ), and analyzed using the LSM software (Zeiss LSM Image Browser Version 3.5.0.376). On each section, a tile scan of the entire hemisphere was imaged, the ROI (striatum) was outlined, and the $20 \times$ field was randomly placed within the ROI for imaging. Following imaging of the full thickness $\mathrm{z}$ stack $(2-\mu \mathrm{m}$ steps) of the $20 \times$ field, the field was manually moved a fixed distance of approximately $400 \mu \mathrm{m}$ in the horizontal and then vertical axis, resulting in 4-6 counting images per striatum per section. BrdU+ cells were quantified using Metamorph Offline (6.0, Universal Imaging Corporation, Downington, Pa., USA) and double-labeled cells were counted manually. Cells were considered double-labeled if colabeling with relevant morphology was seen throughout the extent of the nucleus for BrdU and NeuN, or if the cytoplasmic GFAP markings surrounded the nuclear BrdU marker, when viewed in $\mathrm{x}-\mathrm{y}$ cross-section, as well as in $\mathrm{x}-\mathrm{z}$ and $\mathrm{y}-\mathrm{z}$ cross-sections produced by reconstructions from $z$ stacks taken with the $20 \times$ objective. Cell density was calculated as average number of cells per $20 \times$ field, and cell percentage was calculated as total number of double-labeled cells per total number of BrdU+ cells.

\section{Data Analysis}

Results are expressed as mean \pm SD. For volumetric analysis, one-way analysis of variance (ANOVA) was performed with Student-Newman-Keuls post-hoc test for multiple comparisons. For cell counts, unpaired t test with Fisher's PLSD was used. Pearson correlation coefficients compared statistical relationships. $\mathrm{p}$ values below 0.05 were considered significant. All statistical analyses were performed using StatView (version 5.0.1, SAS software, Cary, N.C., USA).

\section{Results}

Twenty animals underwent transient MCAO and 8 underwent sham surgery; there was no mortality from the procedure. According to the inclusion criterion by MRI imaging, 17 of $20 \mathrm{MCAO}$ animals were included and randomly allocated to MCAO with vehicle $(n=9)$ or MCAO with EPO treatment $(n=8)$. Two pups from the MCAO vehicle group and one from the MCAO EPO group died during the week following the procedure. The remaining survivors were divided as follows: sham surgery with vehicle (VS, $\mathrm{n}=4$ ), sham surgery with EPO (ES, $\mathrm{n}=4)$, MCAO with vehicle (VO, $\mathrm{n}=7$ ), and MCAO with $\mathrm{EPO}(\mathrm{EO}, \mathrm{n}=7)$. Male and female rats were evenly distributed between the 4 groups, with no statistical significance between males and females in any of the analyses (data not shown).

\section{EPO Preserves Hemispheric Brain Volume following $M C A O$}

Animals that received transient MCAO had significant tissue loss in the ipsilateral striatum and parietotemporal cortex at 6 weeks after injury (fig. 1a). In animals that underwent sham surgery, there was no difference in hemispheric volume between VS and ES treatment. In the VO group, there was a significant decrease in percent preserved volume, but this tissue loss was significantly reduced in the EO group, demonstrating a marked protective effect (fig. 1b, c). 
Fig. 1. Evidence that exogenous EPO has a neuroprotective effect at 6 weeks after injury. a Cresyl violet-stained coronal section shows MCAO causes persistent injury and volume loss in the ipsilateral striatum $\left.{ }^{*}\right)$ and cortex $\left({ }^{* *}\right)$ at 6 weeks. b Volume loss is improved following EPO treatment. Hole in contralateral hemisphere represents left hemisphere identifier. c No difference in ratio of ipsilateral, lesioned hemisphere vs. contralateral, control hemisphere volume between the ES and VS sham groups. There is a significant decrease in ipsi/contra hemispheric brain volume in MCAO vs. sham animals $\left({ }^{\#} \mathrm{p}<\right.$ 0.05 vs. VS, ES), with a significant protective effect against hemispheric volume loss in $\mathrm{EO}$ vs. $\mathrm{VO}$ rats $\left({ }^{*} \mathrm{p}<0.004\right.$ vs. VO).
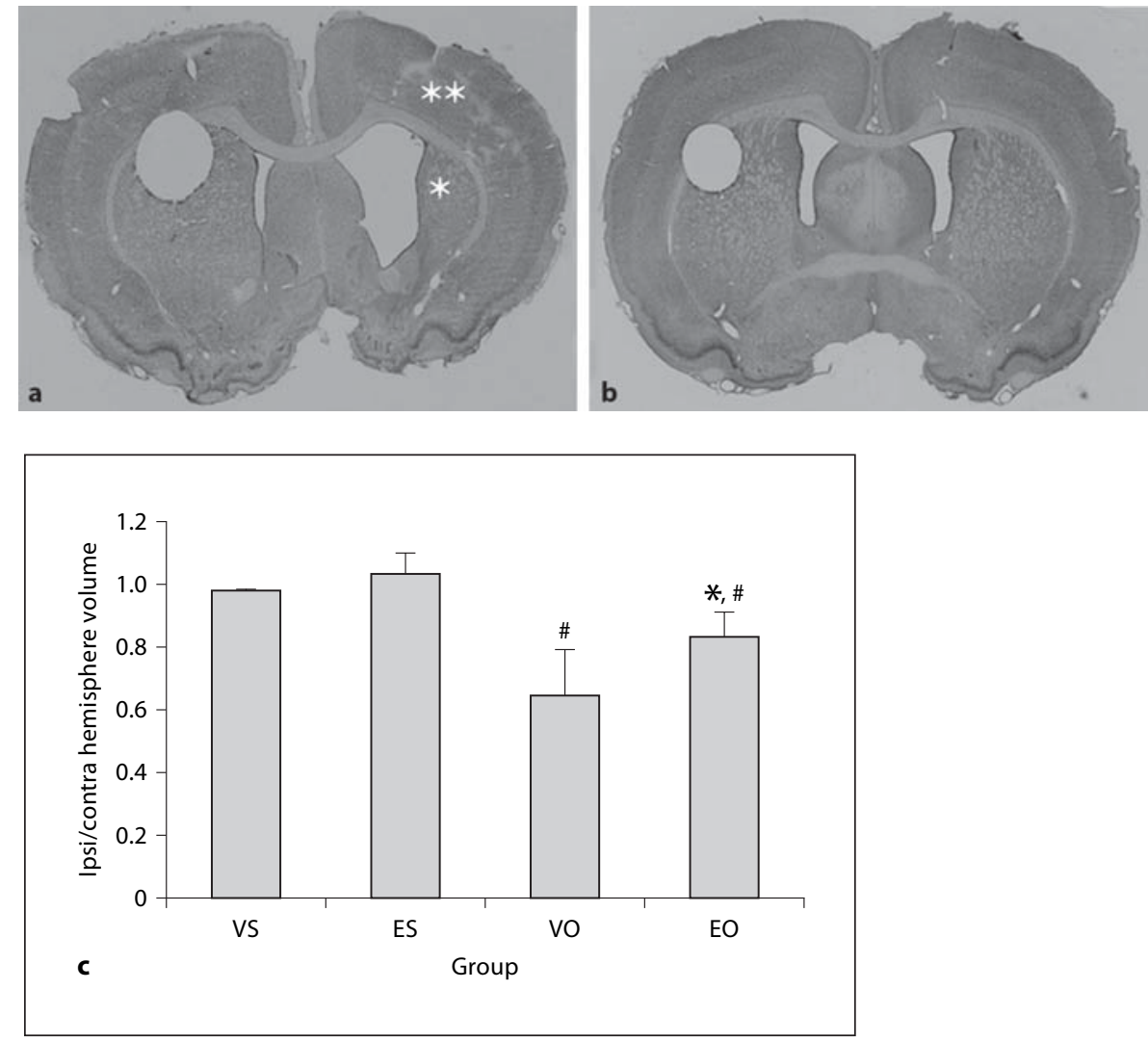

\section{No Difference in SVZ Volume 6 Weeks after MCAO}

On cresyl violet staining, the SVZ is a darkened, narrow band between the corpus callosum and subcallosal striatum adjacent to the ventricular margin rostrally, which widens dorsolaterally beneath the corpus callosum through caudal sections (fig. 2a). Previously, we have shown an increase in SVZ size ipsilaterally 2 weeks after MCAO, with marked expansion rostrally and laterally, which decreased with EPO treatment [12]. In this study, there was no statistically significant difference in SVZ volume between the 4 groups at 6 weeks after injury (fig. 2b). Animals with severe injury did show an increase in SVZ size, with widened morphology (fig. 2c), which correlated with size of injury (fig. 2d); however, there was no difference between EPO and vehicle treatment.

\section{EPO Did Not Increase Density of Newly Generated}

Cells in the Damaged Striatum

On days 7 through 9 following MCAO, animals were injected with BrdU, a thymidine analog incorporated during $S$ phase, to label cells newly generated during this time period after injury. Given previous studies suggest- ing an increase in production of cells from precursors in the SVZ following MCAO and EPO [12, 13, 25], we looked at the production of all BrdU+ cells in the injured areas at 6 weeks. We did not find an increase in the density of newly generated cells following MCAO, in either the VO or the EO group (fig. 3), suggesting that a single dose of EPO may have a larger effect on cell fate than number on days 7 through 9 after injury.

\section{EPO Increases Neurogenesis in Damaged Striatum}

Sections were double-immunostained with antibody to BrdU and NeuN, a neuronal nuclei monoclonal antibody that is a marker for mature neurons, to identify newly generated cells that survived to become neurons in and near the site of injury (fig. 4). EPO treatment led to a significant increase in both the density (fig. 4c) and proportion (fig. $4 \mathrm{~d}$ ) of newly generated neurons in the injured striatum, whereas the numbers in the contralateral striatum were not different from controls (data not shown). In addition, in the sham groups, EPO treatment significantly increased the density of newly generated cells that became neurons (fig. 4c), suggesting that EPO 
Fig. 2. Neither MCAO nor exogenous EPO has an overall significant effect on SVZ volume 6 weeks after injury. a Cresyl violet-stained coronal section showing the right SVZ (marked by arrows) in a sham animal, bordered by the corpus callosum superiomedially, the striatum laterally, and the lateral ventricle medially. b There was no difference in SVZ volumes at 6 weeks after injury between the 4 groups. c SVZ (arrows) in a severely injured animal, with widened morphology rostrally and triangular shape caudally. d SVZ size correlates with severity of hemispheric injury $\left(\mathrm{r}^{2}=0.19, \mathrm{p}<0.04\right)$.

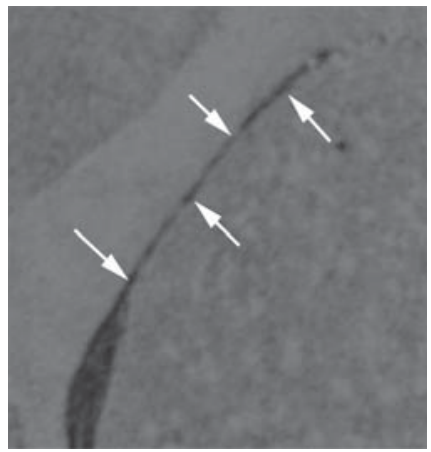

a
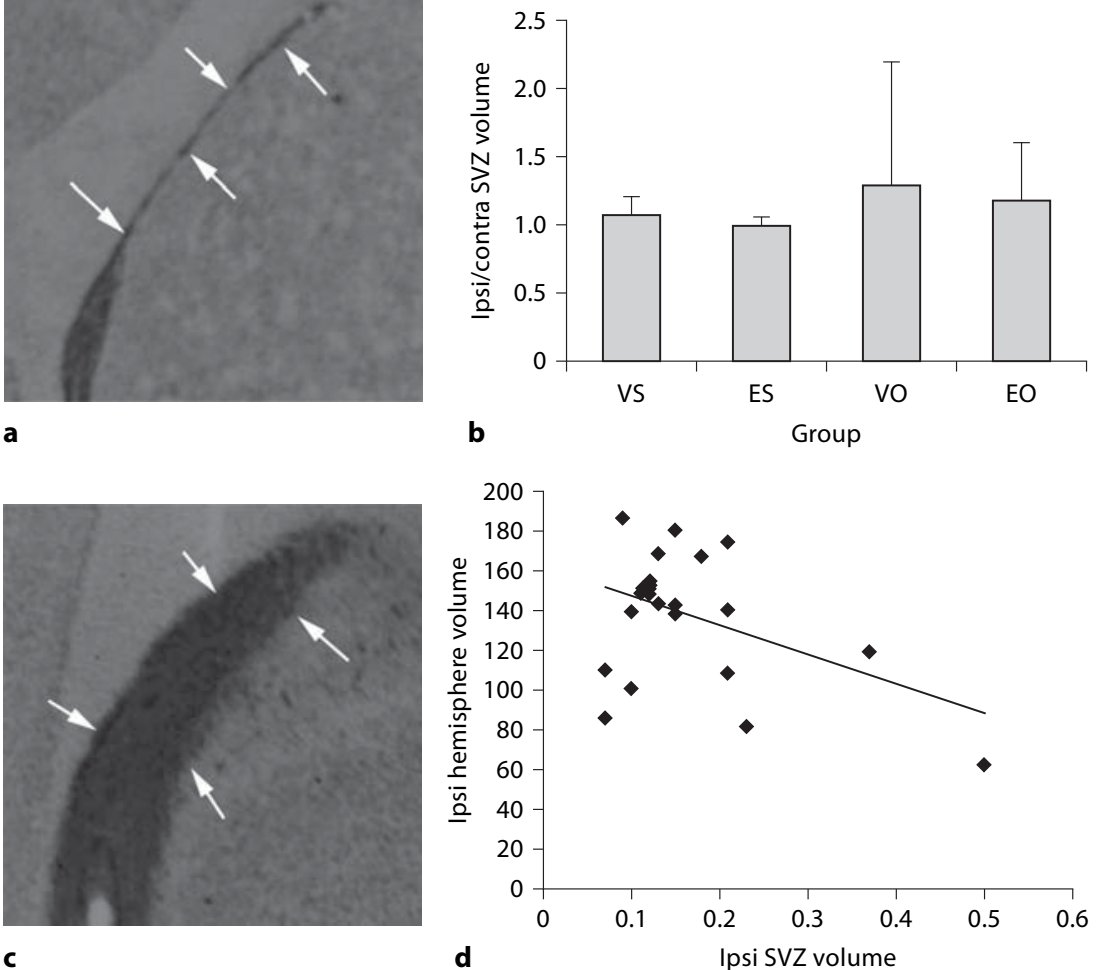

plays a role in cell fate decision, even in the absence of injury, but that MCAO treatment results in a larger increase of new neurons following EPO treatment.

\section{EPO Leads to a Decrease in GFAP-Positive Astrocytes in the Damaged Striatum}

A large number of BrdU+ cells in the injured striatum did not express NeuN, perhaps indicative of gliosis or accumulation of other cell types in the ischemic brain tissue. Therefore, GFAP, an anti-glial fibrillary acidic protein polyclonal antibody that labels astrocytes, was used to examine the role of gliosis following MCAO (fig. 5). In the MCAO groups, there was a significantly reduced proportion (fig. 5c) of newly generated cells that become astrocytes in the striatum following EPO treatment. Likewise, in the sham groups, EPO treatment reduced the percentage of newly generated astrocytes, suggesting a role for EPO in determining cell fate and favoring a neurogenic outcome.

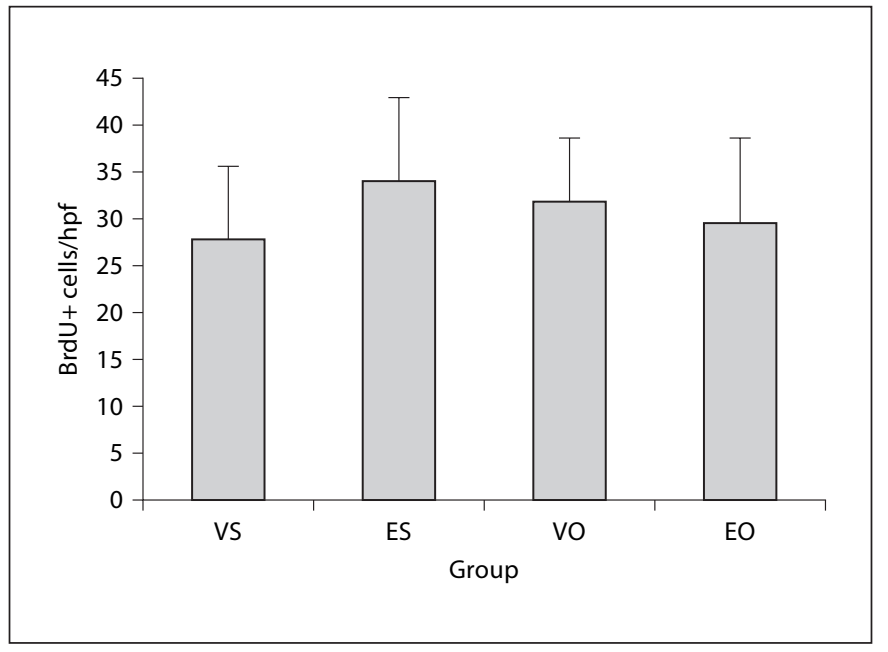

Fig. 3. EPO has no effect on density of newly generated cells in either the sham or MCAO groups. $h p f=20 \times$ field $(412 \times 412 \times$ $25 \mu \mathrm{m})$. 


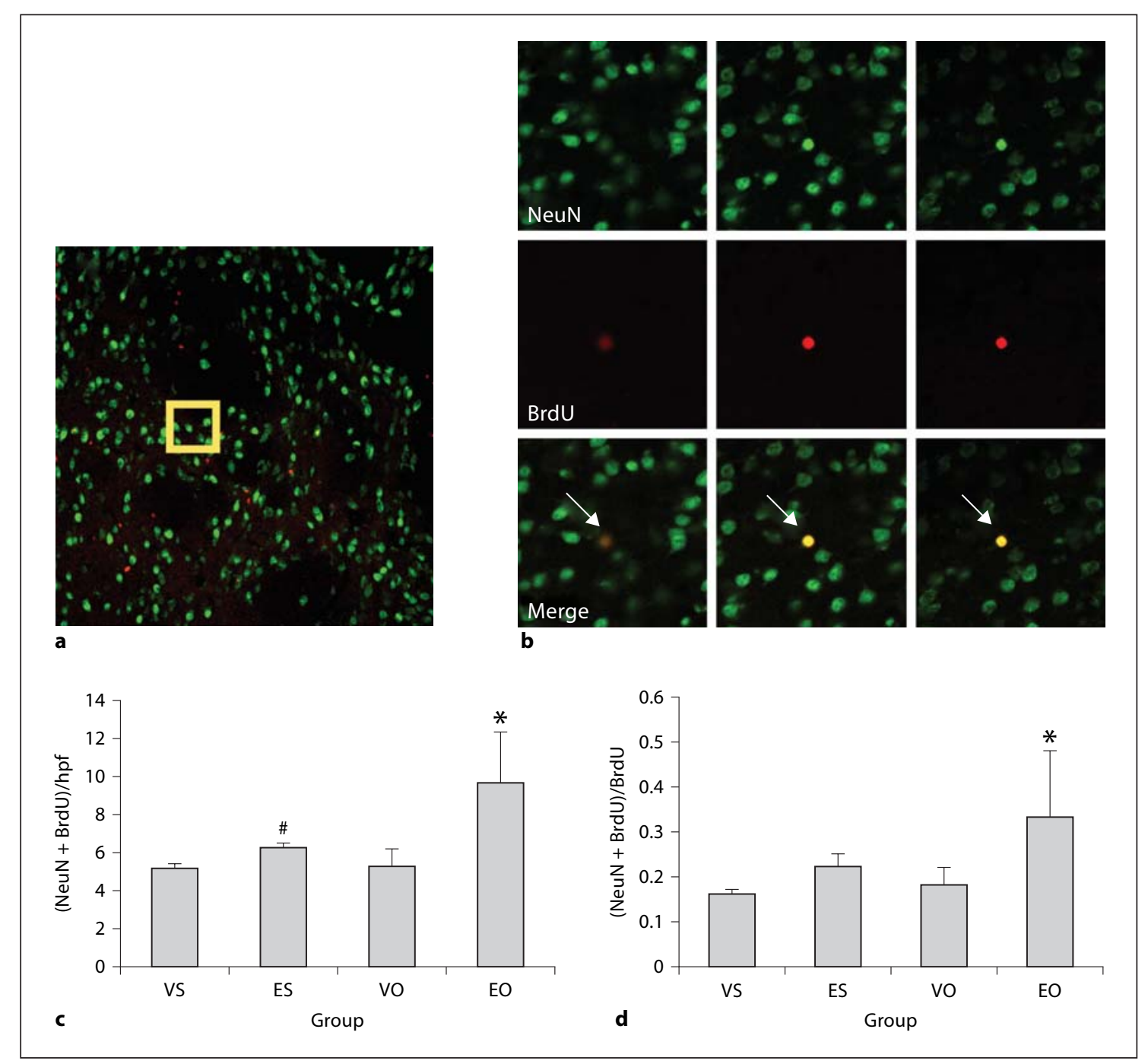

Fig. 4. Evidence for exogenous EPO as a regulator of neurogenesis. Coronal $40-\mu \mathrm{m}$ section of striatum immunostained with antibody to BrdU (red) and NeuN (green) to label newly generated cells that survived to become mature neurons by 6 weeks of age. a $20 \times$ confocal projection image. $\mathbf{b}$ Selection of individual $2-\mu \mathrm{m} \mathrm{z}$ steps of $\mathrm{NeuN}+$ cells (top), BrdU+ cells (middle), and merge images (bottom). Colabeled cell marked by arrow. c EPO increased the density of newly generated neurons in sham $\left({ }^{\#} \mathrm{p}<0.05\right)$ and MCAO animals $\left({ }^{*} \mathrm{p}<0.001 \mathrm{vs}\right.$. VO). d EPO increased the proportion of newly generated cells that become neurons in MCAO animals $\left({ }^{*} \mathrm{p}<0.03 \mathrm{vs}\right.$. $\mathrm{VO})$.

\section{Discussion}

The results of this study demonstrate that a single dose of exogenous EPO immediately following transient MCAO preserves brain tissue and decreases infarct volume 6 weeks after injury. EPO treatment leads to an increase in the percentage of newly born neurons in the injured areas, while decreasing the percentage of astrocytes, without changing the overall density of newly born $(\mathrm{BrdU}+)$ cells. This suggests a dual role for EPO, promot- ing not just neuroprotection, but also neurogenesis possibly via the alteration of cell fate decisions, as opposed to increased production of all cell types.

EPO has previously been shown to preserve brain volume following neonatal hypoxia-ischemia (HI) $[6,8,14]$, and to decrease infarct volume following transient $\mathrm{MCAO}$ in P7 rats [15]. We chose a single dose of EPO immediately following injury, as opposed to during or prior to injury, to more closely approximate a clinical scenario where EPO may be used for treatment. This model, simi- 


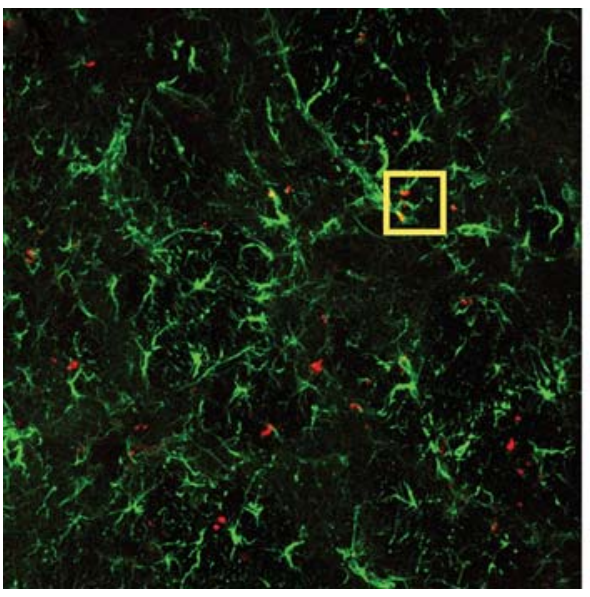

a

Fig. 5. EPO decreases astrogliosis following MCAO. a $20 \times$ confocal projection image. $\mathbf{b}$ Individual $\mathrm{z}$ steps of individually labeled GFAP+ cells (top) and BrdU+ cells (middle), with merged images (bottom). Colabeled cells are marked by arrows. c MCAO increases proportion of newly generated astrocytes, while EPO decreases astrogliosis in both MCAO and sham animals ( ${ }^{\#} \mathrm{p}<0.04$ vs. VS, VO, EO; ${ }^{*} \mathrm{p}<0.03$ vs. VO, VS, ES; $\wedge \mathrm{p}<0.03$ vs. VS, ES, $\mathrm{EO})$.
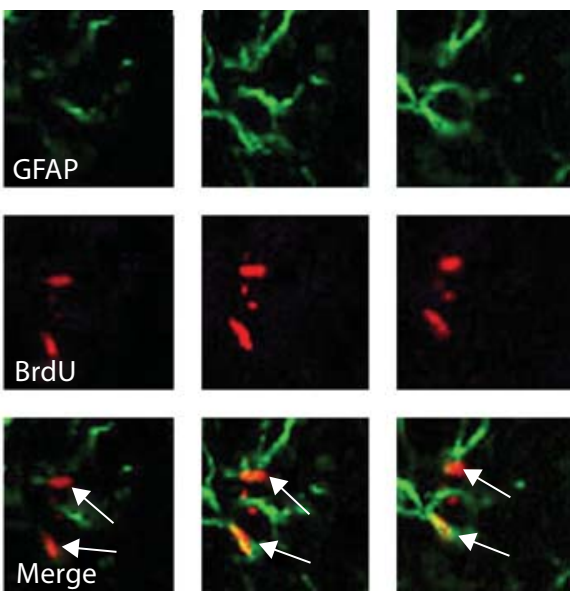

b

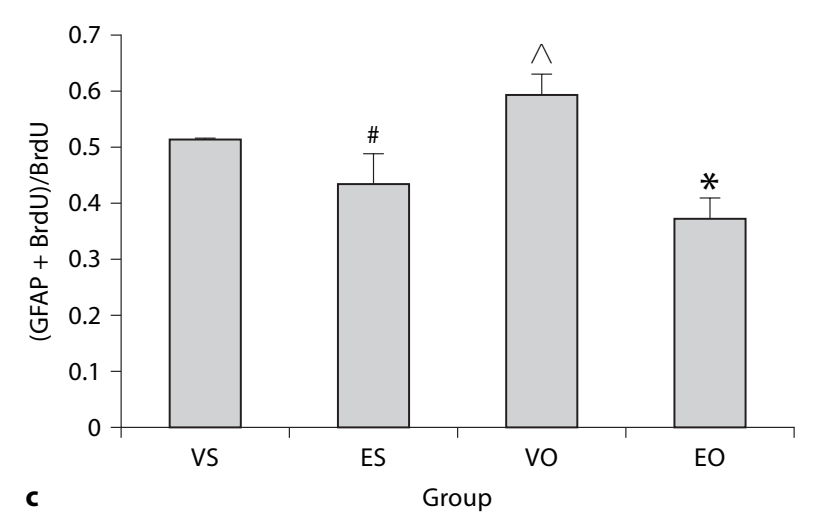

lar to other postinjury dosing regimens $[14,15]$, has previously been demonstrated to confer short-term histological and functional benefit [12]. In our model, similar to our findings at 2 weeks, there still persists preservation of brain tissue at 6 weeks. While EPO had no effect on volumes in sham animals, the significant difference in injured animals suggests neuroprotection. The mechanism by which this occurs has not been entirely elucidated, but it may involve a decrease in intracellular calcium [21], inhibition of nitric oxide-induced death [22], or modulation of the inflammatory [17-19] or angiogenic responses [13, 23, 24]. In transient MCAO, Sola et al. [15] found a significant decrease in TUNEL-positive cells with EPO, suggesting an antiapoptotic effect. EPO induces an increase in phosphorylated Janus kinase 2 and signal transducer and activator of transcription-5 (STAT5) expression, resulting in upregulation of antiapoptotic genes such as Bcl-xL $[15,16,25,35]$ and NF-кB [25]. EPO does not appear to protect against early injury in the first $6 \mathrm{~h}$ [8], rather at later time points, suggesting a delay is required for the responsible mechanism. This may be related to upregulation of EPO-R, synthesis of protein, or activation of a cascade that results in neuroprotection.

While these results suggest a role for EPO in preservation of tissue, this may not be sufficient for long-term improvement, and neurogenesis may be a necessary response. In rodents, neurogenesis is thought to primarily occur during embryogenesis, with the exceptions being the olfactory bulb and dentate gyrus $[36,37]$. The SVZ is a source of neurons that migrate to the olfactory bulb [38, 39], and this neurogenesis peaks during the first 2 postnatal weeks [40]. Previously, the SVZ was found to become less cellular 3 weeks after HI [41], but other studies have found an increase in ipsilateral SVZ size, proportional to the size of hemispheric damage [27, 28, 42], with an increase in progenitor cells [43] and neuroblast migration toward the site of injury $[27,28]$; however, these in- 
creases in SVZ size and cellularity following injury do not persist $[27,28]$. Increases in BrdU+ density in the ipsilateral SVZ at 2 weeks following HI [44], quinolinic acidinduced seizure [45], and MCAO [27, 30, 46, 47] decrease to or near control levels 2-4 weeks later.

Local injury may initiate pathways that increase precursor proliferation, but also enhance migration and determine cell fate. Parent et al. [47] found a transient increase in SVZ neurogenesis 2 weeks after MCAO, without changes in astrocytic markers, and migration and differentiation of region appropriate neurons in the peri-infarct striatum. Collin et al. [45] also found an increase in SVZ cell proliferation and newly generated neuroblasts in the ipsilateral striatum following quinolinic acid-induced injury, with a gradient from medial to lateral, suggesting neurogenesis through recruitment of neuroblasts into the striatum. Arvidsson et al. [46] noticed an increase in $\mathrm{BrdU}+/ \mathrm{NeuN}+$ cells in the lesioned striatum after stroke, as well as massive gliosis, but $80 \%$ of the newly generated neurons disappeared between 2 and 6 weeks. This suggests that following brain injury, new neurons migrate into the damaged areas, but local trophic factors/signals that play a role in migration and differentiation may be inadequate for survival.

EPO does show promise as a trophic factor that may support cell differentiation, survival, and possible incorporation into neural networks. EPO increases the density of newly born cells and oligodendrocy te precursors in the striatum, corpus callosum, and SVZ [48]. In our study, there was no overall difference in SVZ volume between the groups at 6 weeks after injury, regardless of MCAO or EPO treatment. Hypertrophy was still seen in the animals with the most severe injury, suggesting a relationship between injury size and precursor proliferation. Consistent with this, MCAO caused an increase in ipsilateral SVZ size and change in morphology at 2 weeks after injury, which was reduced with EPO treatment [12]. At 6 weeks, the overall lack of difference may represent a return of SVZ size to normal following migration [30] or a decrease in precursor cell proliferation and number after the infarct has evolved. In addition, while newly generated neurons migrate from the SVZ following injury, new astrocytes may proliferate locally as well, so the exact role of the SVZ in producing different cell types following EPO is not clear. To differentiate between these hypotheses will require careful quantification of cell type and number in the SVZ and surrounding infarct areas at sequential time points following injury.

The most striking finding of our study is a shift from astrocytic to neuronal cell fate. In this model, despite a lack of effect on SVZ size, there was an increased density and percentage of newly generated neurons (co-labeled with BrdU and NeuN) in the injured striatum. We did not, however, find an increased density of newly born $(\mathrm{BrdU}+)$ cells. Normally after brain injury, extensive gliosis occurs near the site of injury [27,28,44], which persists in contrast to newly generated neurons. Plane et al. [27] found increased BrdU+ and GFAP+ cells in the injured hemisphere at 1 week following $\mathrm{HI}$, concentrated in the ipsilateral white matter and periventricular striatum. At 2 weeks, many newly generated neurons and astrocytes were located near the lesioned striatum, and at 3 weeks widespread gliosis remained while new neurons decreased. Ong et al. [28] saw an increase in newly generated neuroblasts and astrocytes 2 weeks following HI, but only astrocytes persisted at 4 weeks. Shingo et al. [25] found that hypoxia, via elevated EPO expression and blocked by anti-EPO antibody, induced a two- to threefold increase in numbers of neurons/sphere in vitro. This increase in neuronal production was mimicked by EPO in a dose-dependent manner, but did not increase total cell number or astroglial cells vs. controls, and decreased the production of secondary stem cells. In vivo, intraventricular EPO increased newly generated neurons that migrated to the olfactory bulb, with rapid phosphorylation of STAT5 and upregulation of NF- $\kappa$ B. This resulted in an increase in neurogenesis and a corresponding decrease in secondary stem cells, suggesting a role for NF$\kappa \mathrm{B}$ in directing multipotent precursors to the neuronal lineage [25]. In addition, TUNEL labeling did not show differences between EPO and non-EPO treated, signifying a role for EPO in neurogenesis as opposed to cell survival.

What mechanism underlies this change in cell fate commitment? EPO is increased by hypoxia and brain injury, and EPO and EPO-R have been detected in multiple cell lines in the brain, suggesting EPO could work in autocrine-paracrine fashion and result in neuroprotection and neurogenesis $[5,25]$. EPO and EPO-R are weakly expressed in the adult brain [49], but are upregulated in the ischemic penumbra following permanent focal ischemia in adult mice [5]. EPO and EPO-R play important roles in embryonic development, including radial glia development, starting at E11 [50]. Upregulation of astrocytes and their precursors, such as radial glia, may be the source of newly generated neurons in the postnatal brain [51]. Fagel et al. [42] found an increased number of cells of the astroglial lineage proliferating in the neurogenic zones during recovery from perinatal hypoxia. These cells, via glial-derived factors or neuroblast production from ra- 
dial glia, may influence production and migration of cells to injured areas.

In this model of neonatal brain injury, a single dose of EPO immediately after injury preserved brain volume and increased neurogenesis while decreasing the glial response in the injured area. An important question to answer involves the long-term functional outcomes in this model. We have previously seen improved behavioral performance at 2 weeks after injury. Others have shown long-term improvements with EPO in visuospatial learning and memory [14]. Given the evolution of injury over time [8], it remains to be seen what dose and treatment regimen results in the best long-term outcomes. Taken together with previous studies, our observations suggest that EPO may be useful both early, for its direct neuro- protective effect, and late, to influence progenitor cell fate and maximize neurogenesis. The findings of this study will need to be correlated with long-term behavioral performance, and the optimal dosing regimens defined to maximize the neurogenesis that occurs a week or later after injury.

\section{Acknowledgements}

This work was supported by a grant from Johnson \& Johnson Pharmaceutical Research and Development, L.L.C., Raritan, N.J.; March of Dimes Birth Defect Foundation 6-FY 2006-465, and NS 35902 to D.M.F. The authors would like to acknowledge the technical assistance of Joel Faustino, BS.

\section{References}

1 Lynch JK, Nelson KB: Epidemiology of perinatal stroke. Curr Opin Pediatr 2001;13: 499-505.

- 2 Derugin N, Wendland M, Muramatsu K, Roberts TP, Gregory G, Ferriero DM, Vexler ZS: Evolution of brain injury after transient middle cerebral artery occlusion in neonatal rats. Stroke 2000;31:1752-1761.

> Mu D, Jiang X, Sheldon RA, Fox CK, Hamrick SE, Vexler ZS, Ferriero DM: Regulation of hypoxia-inducible factor lalpha and induction of vascular endothelial growth factor in a rat neonatal stroke model. Neurobiol Dis 2003;14:524-534.

4 Sadamoto Y, Igase K, Sakanaka M, Sato K, Otsuka H, Sakaki S, Masuda S, Sasaki R: Erythropoietin prevents place navigation disability and cortical infarction in rats with permanent occlusion of the middle cerebral artery. Biochem Biophys Res Commun 1998; 253:26-32.

5 Bernaudin M, Marti HH, Roussel S, Divoux D, Nouvelot A, MacKenzie ET, Petit E: A potential role for erythropoietin in focal permanent cerebral ischemia in mice. J Cereb Blood Flow Metab 1999;19:643-651.

-6 Aydin A, Genc K, Akhisaroglu M, Yorukoglu K, Gokmen N, Gonullu E: Erythropoietin exerts neuroprotective effect in neonatal rat model of hypoxic-ischemic brain injury. Brain Dev 2003;25:494-498.

7 Brines ML, Ghezzi P, Keenan S, Agnello D, de Lanerolle NC, Cerami C, Itri LM, Cerami A: Erythropoietin crosses the blood-brain barrier to protect against experimental brain injury. Proc Natl Acad Sci USA 2000;97: 10526-10531.

8 Matsushita H, Johnston MV, Lange MS, Wilson MA: Protective effect of erythropoietin in neonatal hypoxic ischemia in mice. Neuroreport 2003;14:1757-1761. $\checkmark$ Kumral A, Ozer E, Yilmaz O, Akhisaroglu M, Gokmen N, Duman N, Ulukus C, Genc S, Ozkan H: Neuroprotective effect of erythropoietin on hypoxic-ischemic brain injury in neonatal rats. Biol Neonate 2003;83:224228.

10 Sun Y, Zhou C, Polk P, Nanda A, Zhang JH: Mechanisms of erythropoietin-induced brain protection in neonatal hypoxia-ischemia rat model. J Cereb Blood Flow Metab 2004;24:259-270.

-11 Siren AL, Fratelli M, Brines M, Goemans C, Casagrande S, Lewczuk P, Keenan S, Gleiter C, Pasquali C, Capobianco A, Mennini T, Heumann R, Cerami A, Ehrenreich H, Ghezzi P: Erythropoietin prevents neuronal apoptosis after cerebral ischemia and metabolic stress. Proc Natl Acad Sci USA 2001;98: 4044-4049.

12 Chang YS, Mu D, Wendland M, Sheldon RA, Vexler ZS, McQuillen PS, Ferriero DM: Erythropoietin improves functional and histological outcome in neonatal stroke. Pediatr Res 2005;58:106-111.

13 Wang L, Zhang Z, Wang Y, Zhang R, Chopp M: Treatment of stroke with erythropoietin enhances neurogenesis and angiogenesis and improves neurological function in rats. Stroke 2004;35:1732-1737.

14 Kumral A, Uysal N, Tugyan K, Sonmez A, Yilmaz O, Gokmen N, Kiray M, Genc S, Duman N, Koroglu TF, Ozkan H, Genc K: Erythropoietin improves long-term spatial memory deficits and brain injury following neonatal hypoxia-ischemia in rats. Behav Brain Res 2004;153:77-86.
15 Sola A, Rogido M, Lee BH, Genetta T, Wen TC: Erythropoietin after focal cerebral ischemia activates the Janus kinase-signal transducer and activator of transcription signaling pathway and improves brain injury in postnatal day 7 rats. Pediatr Res 2005;57: 481-487.

16 Digicaylioglu M, Lipton SA: Erythropoietinmediated neuroprotection involves crosstalk between Jak2 and NF-kappaB signalling cascades. Nature 2001;412:641-647.

17 Villa P, Bigini P, Mennini T, Agnello D, Laragione T, Cagnotto A, Viviani B, Marinovich M, Cerami A, Coleman TR, Brines M, Ghezzi $\mathrm{P}$ : Erythropoietin selectively attenuates cytokine production and inflammation in cerebral ischemia by targeting neuronal apoptosis. J Exp Med 2003;198:971-975.

18 Agnello D, Bigini P, Villa P, Mennini T, Cerami A, Brines ML, Ghezzi P: Erythropoietin exerts an anti-inflammatory effect on the CNS in a model of experimental autoimmune encephalomyelitis. Brain Res 2002; 952:128-134.

19 Arvin B, Neville LF, Barone FC, Feuerstein GZ: The role of inflammation and cytokines in brain injury. Neurosci Biobehav Rev 1996; 20:445-452.

20 Dzietko M, Felderhoff-Mueser U, Sifringer M, Krutz B, Bittigau P, Thor F, Heumann R, Buhrer C, Ikonomidou C, Hansen $\mathrm{HH}$ : Erythropoietin protects the developing brain against $\mathrm{N}$-methyl-D-aspartate receptor antagonist neurotoxicity. Neurobiol Dis 2004;15:177-187.

21 Morishita E, Masuda S, Nagao M, Yasuda Y, Sasaki R: Erythropoietin receptor is expressed in rat hippocampal and cerebral cortical neurons, and erythropoietin prevents in vitro glutamate-induced neuronal death. Neuroscience 1997;76:105-116. 
-22 Sakanaka M, Wen TC, Matsuda S, Masuda S, Morishita E, Nagao M, Sasaki R: In vivo evidence that erythropoietin protects neurons from ischemic damage. Proc Natl Acad Sci USA 1998;95:4635-4640.

-23 Yamaji R, Okada T, Moriya M, Naito M, Tsuruo T, Miyatake K, Nakano Y: Brain capillary endothelial cells express two forms of erythropoietin receptor mRNA. Eur J Biochem 1996;239:494-500.

24 Chong ZZ, Kang JQ, Maiese K: Angiogenesis and plasticity: role of erythropoietin in vascular systems. J Hematother Stem Cell Res 2002;11:863-871.

25 Shingo T, Sorokan ST, Shimazaki T, Weiss S: Erythropoietin regulates the in vitro and in vivo production of neuronal progenitors by mammalian forebrain neural stem cells. J Neurosci 2001;21:9733-9743.

-26 Lu D, Mahmood A, Qu C, Goussev A, Schallert T, Chopp M: Erythropoietin enhances neurogenesis and restores spatial memory in rats after traumatic brain injury. J Neurotrauma 2005;22:1011-1017.

-27 Plane JM, Liu R, Wang TW, Silverstein FS, Parent JM: Neonatal hypoxic-ischemic injury increases forebrain subventricular zone neurogenesis in the mouse. Neurobiol Dis 2004;16:585-595.

28 Ong J, Plane JM, Parent JM, Silverstein FS: Hypoxic-ischemic injury stimulates subventricular zone proliferation and neurogenesis in the neonatal rat. Pediatr Res 2005;58:600606.

-29 Jin K, Minami M, Lan JQ, Mao XO, Batteur S, Simon RP, Greenberg DA: Neurogenesis in dentate subgranular zone and rostral subventricular zone after focal cerebral ischemia in the rat. Proc Natl Acad Sci USA 2001 98:4710-4715.

30 Zhang RL, Zhang ZG, Zhang L, Chopp M: Proliferation and differentiation of progenitor cells in the cortex and the subventricular zone in the adult rat after focal cerebral ischemia. Neuroscience 2001;105:33-41.

- 31 Hagberg H, Bona E, Gilland E, Puka-Sundvall $M$ : Hypoxia-ischaemia model in the 7day-old rat: possibilities and shortcomings. Acta Paediatr Suppl 1997;422:85-88.

-32 Parent JM: Injury-induced neurogenesis in the adult mammalian brain. Neuroscientist 2003;9:261-272.
33 Regeur L, Pakkenberg B: Optimizing sampling designs for volume measurements of components of human brain using a stereological method. J Microsc 1989;155:113121.

34 Paxinos G: The Rat Brain in Stereotaxic Coordinates. San Diego, Academic Press, 1986.

35 Wen TC, Sadamoto Y, Tanaka J, Zhu PX, Nakata K, Ma YJ, Hata R, Sakanaka M: Erythropoietin protects neurons against chemical hypoxia and cerebral ischemic injury by upregulating $\mathrm{Bcl}-\mathrm{xL}$ expression. J Neurosci Res 2002;67:795-803.

36 Luskin MB, Parnavelas JG, Barfield JA: Neurons, astrocytes, and oligodendrocytes of the rat cerebral cortex originate from separate progenitor cells: an ultrastructural analysis of clonally related cells. J Neurosci 1993;13: 1730-1750.

37 Lois C, Alvarez-Buylla A: Proliferating subventricular zone cells in the adult mammalian forebrain can differentiate into neurons and glia. Proc Natl Acad Sci USA 1993;90: 2074-2077.

38 Levison SW, Chuang C, Abramson BJ, Goldman JE: The migrational patterns and developmental fates of glial precursors in the rat subventricular zone are temporally regulated. Development 1993;119:611-622.

39 Levison SW, Goldman JE: Both oligodendrocytes and astrocytes develop from progenitors in the subventricular zone of postnatal rat forebrain. Neuron 1993;10:201212.

40 Bayer SA: 3H-thymidine-radiographic studies of neurogenesis in the rat olfactory bulb. Exp Brain Res 1983;50:329-340.

- 41 Levison SW, Rothstein RP, Romanko MJ, Snyder MJ, Meyers RL, Vannucci SJ: Hypoxia/ischemia depletes the rat perinatal subventricular zone of oligodendrocyte progenitors and neural stem cells. Dev Neurosci 2001;23:234-247.

42 Fagel DM, Ganat Y, Silbereis J, Ebbitt T, Stewart W, Zhang H, Ment LR, Vaccarino FM: Cortical neurogenesis enhanced by chronic perinatal hypoxia. Exp Neurol 2006; 199:77-91.
43 Felling RJ, Snyder MJ, Romanko MJ, Rothstein RP, Ziegler AN, Yang Z, Givogri MI, Bongarzone ER, Levison SW: Neural stem/ progenitor cells participate in the regenerative response to perinatal hypoxia/ischemia. J Neurosci 2006;26:4359-4369.

44 Zaidi AU, Bessert DA, Ong JE, Xu H, Barks JD, Silverstein FS, Skoff RP: New oligodendrocytes are generated after neonatal hypoxic-ischemic brain injury in rodents. Glia 2004;46:380-390.

45 Collin T, Arvidsson A, Kokaia Z, Lindvall O: Quantitative analysis of the generation of different striatal neuronal subtypes in the adult brain following excitotoxic injury. Exp Neurol 2005;195:71-80.

-46 Arvidsson A, Collin T, Kirik D, Kokaia Z, Lindvall O: Neuronal replacement from endogenous precursors in the adult brain after stroke. Nat Med 2002;8:963-970.

47 Parent JM, Vexler ZS, Gong C, Derugin N, Ferriero DM: Rat forebrain neurogenesis and striatal neuron replacement after focal stroke. Ann Neurol 2002;52:802-813.

-48 Zhang PB, Liu Y, Li J, Kang QY, Tian YF, Chen XL, Zhao JJ, Shi QD, Song TS, Qian YH: Ependymal/subventricular zone cells migrate to the peri-infarct region and differentiate into neurons and astrocytes after focal cerebral ischemia in adult rats. Di Yi Jun Yi Da Xue Xue Bao 2005;25:1201-1206.

- 49 Siren AL, Knerlich F, Poser W, Gleiter CH, Bruck W, Ehrenreich H: Erythropoietin and erythropoietin receptor in human ischemic/ hypoxic brain. Acta Neuropathol (Berl) 2001;101:271-276.

50 Knabe W, Knerlich F, Washausen S, Kietzmann T, Siren AL, Brunnett G, Kuhn HJ, Ehrenreich H: Expression patterns of erythropoietin and its receptor in the developing midbrain. Anat Embryol (Berl) 2004;207: 503-512.

51 Morshead CM, Garcia AD, Sofroniew MV, van Der Kooy D: The ablation of glial fibrillary acidic protein-positive cells from the adult central nervous system results in the loss of forebrain neural stem cells but not retinal stem cells. Eur J Neurosci 2003;18:7684. 